\title{
ESTUDANTES COTISTAS NEGROS E AÇÕES AFIRMATIVAS NO ENSINO SUPERIOR
}

\author{
Benedito Gonçalves Eugenio' \\ Julia Algarra ${ }^{2}$
}

\section{RESUMO}

Neste trabalho, analisamos o percurso de escolarização de estudantes negros dos meios populares que ingressaram no ensino superior por meio da política de ações afirmativas. Foram entrevistados 4 estudantes cotistas negros do curso de Direito da Universidade Estadual do Sudoeste da Bahia-UESB. A pesquisa é qualitativa, do tipo exploratória. O estudo realizado nos permitiu compreender como constituiu-se 0 processo de educação de estudantes negros até a chegada ao Ensino Superior, bem como sua percepção acerca da escolarização e da vivência do racismo.

Palavras-chave: Acesso e Permanência. Estudantes Negros. Ensino Superior.

\section{BLACK STUDENTS, RACISM AND AFFIRMATIVE ACTIONS IN HIGHER EDUCATION}

\begin{abstract}
In this work, we analyze the schooling pathway of black students who entered higher education by means of affirmative action policy. Four black students from the law undergraduate course of the State University of Southwestern Bahia - UESB were interviewed. The research design is exploratory and qualitative. The study allows us to understand the process of education of black students until they enter Higher Education, as well as their perception about schooling and their experience with racism.
\end{abstract}

Keywords: Access and Permanence. Black Students. Higher Education.

\footnotetext{
1 Doutorado em Educação pela Universidade Estadual de Campinas. Docente da Universidade Estadual do Sudoeste da Bahia. Departamento de Filosofia e Ciências Humanas. Programa de Pós-graduação em Ensino (PPGEn). E-mail: beneditoeugenio@bol.com.br
}

2 Mestranda pelo Programa de Pós-graduação em Relações Étnicas e Contemporaneidade (UESB). E-mail: juuh_algarra@hotmail.com 


\section{ESTUDIANTES COTISTAS NEGROS Y ACCIONES AFIRMATIVAS EN LA ENSEÑANZA SUPERIOR}

\section{RESUMEN}

En este trabajo, analizamos el recorrido de escolarización de estudiantes negros de los medios populares que ingresaron en la enseñanza superior por medio de la política de acciones afirmativas. Se entrevistaron 4 estudiantes cotistas negros del curso de Derecho de la Universidad Estadual del Sudoeste de Bahía - UESB. La investigación es cualitativa, de tipo exploratorio. El estudio realizado nos permite comprender cómo se constituyó el proceso de educación de estudiantes negros hasta la llegada a la Enseñanza Superior, así como su percepción acerca de la escolarización y la vivencia del racismo.

Palabras clave: Acceso y Permanencia. Estudiantes Negros. Enseñanza Superior.

\section{INTRODUÇÃO}

No Brasil, a implementação de políticas públicas de ações afirmativas ocorreu somente a partir do processo de redemocratização do país, "[...] quando diferentes grupos e organizações sociais, antes silenciados pelo regime autoritário, passaram a demandar direitos abertamente" (DAFLON; FERES; CAMPOS, 2013, p. 306 - 307). Contudo, esse não foi um processo fácil.

A partir da experiência inicial da UERJ e UENF, outras universidades federais e estaduais implementaram ações afirmativas para não-brancos em seus processos de seleção. Essas políticas podem ser entendidas como medidas de discriminação positiva. De acordo com Feres Jr. (2004, p. 297):

a ação afirmativa é só mais uma política do Estado de Bem-Estar Social. Ela se assenta sobre a constatação de que uma parcela da população tem suas chances de gozar dos benefícios da vida em sociedade em pé de igualdade com seus concidadãos seriamente diminuídas, e que a proteção formal contra a discriminação dessa parcela, ou seja, as leis que coíbem a discriminação racial, baseadas no princípio universal da não-discriminação, não são eficazes.

Assim sendo, as políticas afirmativas foram, inicialmente, propostas por movimentos sociais que lutavam pela inclusão de determinados segmentos da sociedade, aos quais foram, historicamente, negados seus direitos.

A política de ação afirmativa, segundo Salvador (2011, p. 39): 
[...] tem que agir em várias esferas da sociedade, com múltiplos objetivos, que vão além de uma proposta de inclusão social. Na verdade é uma política que inclui nas áreas mais importantes para a integração social, como a educação e o mercado de trabalho, além de lidar com complexas questões sociais da atualidade, como a desigualdade, a diversidade ou a discriminação.

As políticas de ações afirmativas têm grande importância para a sociedade brasileira, uma vez que o seu caráter transformador ficou conhecido após a implementação de uma das modalidades de ações afirmativas, a política de cotas nas universidades, causando um grande impacto na sociedade, pois possibilitaram através disso discussões, reflexões e questionamentos sobre o que até então era desconhecido por boa parte da população.

Daflon, Feres e Campos (2013, p. 3), apontam que mesmo transcorridos mais de dez anos da implementação das primeiras políticas de ação afirmativa nas universidades brasileiras e mesmo com a aprovação da Lei $n^{\circ}$ 12.711, de 29 de agosto de 2012, que criou uma política de reserva de vagas para alunos de escola pública, pretos/pardos e indígenas, ainda não há um balanço sistemático sobre essas medidas; no entanto, reconhece que essas políticas tendem a alterar significativamente o panorama do ensino superior no país.

Assim sendo, as ações afirmativas são concebidas como "políticas que visam, sobretudo, a tratar os indivíduos em condições de igualdade, independentemente de sua cor, raça, sexo, geração, origem nacional, opção religiosa, orientação sexual, dentre outras características" (VIEIRA; MEDEIROS, 2012, p. 197), recaindo, então, sobre a materialização da igualdade, permitindo oportunidades iguais para todos, mas para que isto aconteça o Estado precisa posicionar-se para que haja a garantia dessa igualdade.

Vieira e Medeiros (2012, p.198) afirmam ainda que "As políticas de ação afirmativa parecem, neste sentido, estar circunscritas a um determinado projeto cujas premissas políticas e filosóficas apresentam-se na 
igualdade entre os homens, em um contexto de 'apagamento' das diferenças".

Instituições privadas também podem aderir a políticas de ação afirmativa. Podemos observar isso nas empresas, por exemplo, no que se refere às políticas de reserva de vagas para pessoas com necessidades especiais, tornando-se uma maneira de promover a redução de desigualdades entre raça, gênero, e outros "marcadores" da diferença. A esse respeito, Estácio (2013, p. 1) afirma que:

As ações afirmativas se referem a políticas e mecanismos de inclusão concebidos por entidades públicas, privadas e por órgãos dotados de competência jurisdicional, com vistas à concretização de um objetivo constitucional universalmente reconhecido, o da efetiva igualdade de oportunidades a que todos os seres humanos têm direito e que sustenta o tratamento desigual aos desiguais.

Portanto, as políticas de ação afirmativa vêm confirmar e fazer com que os sujeitos sociais percebam o quanto vivemos em uma sociedade pluralista e diversa, com culturas, comportamentos, tradições e hábitos diferentes, pois estamos longe de nos tornarmos uma sociedade homogênea, mas isto não faz com que um grupo se torne melhor ou pior que outro. Por esse e outros motivos é que necessitamos discutir cada vez mais sobre as políticas de ação afirmativa, para que os sujeitos tenham acesso aos debates e discussões acerca do tema em questão, pois a maior parte da sociedade ainda desconhece o assunto e, por isso, torna-se contrária a essas políticas, alegando ser uma forma de "privilégio".

Neste artigo, apresentamos narrativas de estudantes cotistas, autodeclarados negros e regularmente matriculados no segundo curso mais concorrido da UESB, Direito. Nosso objetivo é analisar, a partir de entrevistas com estudantes negros(as) desse curso, como constituiu-se sua percepção acerca das ações afirmativas e da vivência cotidiana do racismo.

\section{CONSIDERAÇÕES METODOLÓGICAS}

Para a construção dos dados aqui apresentados, realizamos uma pesquisa qualitativa, do tipo exploratória. Utilizamos entrevistas semi- 
estruturadas com 04 estudantes cotistas, autodeclarados negros, do curso de Direito da Universidade Estadual do Sudoeste da Bahia (UESB), sendo 03 do sexo masculino e 01 do sexo feminino. Os discentes são aqui apresentados por nomes fictícios.

Para Minayo (1994, p.22), a pesquisa qualitativa explicita, em seu desenvolvimento e no interior da análise, elementos subjetivos e objetivos, sentidos, significados, valores, fatos, conflitos, ordens, contradições e, principalmente, as vozes e os sujeitos que dela participaram, voltando-se a um nível de realidade que não pode ser mensurável, controlado, retificado, mas compreendido em processo, sobretudo. Utilizando-nos das palavras da própria autora, diríamos: "[...] trabalha com o universo de significados, motivos, aspirações, crenças, valores e atitudes, o que corresponde a um espaço mais profundo das relações, dos processos e dos fenômenos que não podem ser reduzidos à operacionalização de variáveis".

Ainda segundo Minayo (1994, p.244), "A abordagem qualitativa realiza uma aproximação fundamental e de intimidade entre sujeito e objeto, uma vez que ambos são da mesma natureza: ela se volve com empatia aos motivos, às intenções, aos projetos dos atores, a partir dos quais as ações, as estruturas e as relações tornam-se significativas". A autora ressalta ainda que a abordagem qualitativa só pode ser empregada para a compreensão de fenômenos específicos e delimitáveis, mais pelo seu grau de complexidade interna do que pela sua expressão quantitativa.

Tomando como base essas indicações, selecionamos 4 estudantes autodeclarados negros e ingressantes pela política de ações afirmativas da UESB para a realização das entrevistas. A localização dos entrevistados baseou-se em indicação efetuada pelos próprios estudantes. O roteiro contemplou questões relacionadas à trajetória de escolarização dos discentes e à política de ações afirmativas para acesso e permanência no ensino superior.

As questões foram organizadas nos seguintes blocos: aspectos socioeconômicos dos estudantes; identificação dos seus projetos de estudos ao longo do processo educacional; tempo que levaram para concluir o 
Ensino Fundamental e Médio e de qual rede de ensino advêm; de que maneira a família e outras redes de apoio contribuíram no processo de ascensão social; qual a escolaridade dos pais; se já participou de cursinho pré-vestibular e como foi; se ingressou no ensino superior pelo sistema de cotas e o que pensa sobre as ações afirmativas da Universidade; se já sofreu algum tipo de preconceito; quais as estratégias que utiliza para "permanecer" no meio acadêmico; se tem alguma bolsa/auxílio; se já pensou em desistir do curso e quais os seus planos para quando terminar a faculdade.

Realizamos entrevistas semi-estruturadas, ou seja:

[...] uma escuta ativa e necessária ao diálogo entre os interlocutores na busca de dados pertinentes com o propósito de elucidar o fenômeno. O fato de não possuir uma sequência rígida de questionamentos, não significa que seja uma conversa livre e desprovida de objetivos, pois, com base nos pressupostos teóricos e nas hipóteses construídas no decorrer do trabalho, foi elaborado um roteiro, o qual serviu de itinerário, oferecendo o suporte para a condução da entrevista, evitando a dispersão do assunto e fornecendo princípios norteadores para análise posterior (CARVALHO; EUGENIO, 2011, p. 96-97).

Os sujeitos entrevistados são identificados por nomes fictícios, tendo em vista os princípios éticos de preservação de suas identidades. O espaço empírico foi a Universidade Estadual do Sudoeste da Bahia (UESB), instituição multicampi, com sede em Vitória da Conquista e campi nos municípios de Jequié e ltapetinga. Em 2016 a UESB contava com 47 cursos de graduação e 20 cursos de pós-graduação 17 mestrados acadêmicos, 03 mestrados profissionais e 06 doutorados), além de cursos de especialização. No total, estavam matriculados, em 2015, 8.145 discentes nos cursos de graduação.

A pesquisa foi aprovada pelo Comitê de Ética em Pesquisa da UESB.

\section{RESULTADOS E DISCUSSÃO}

\subsection{Algumas considerações sobre ações afirmativas}

Mesmo com alguns avanços em relação à promoção dos direitos humanos, podemos ainda nos deparar com situações de preconceito e 
discriminação contra mulheres, homossexuais, negros, indígenas, pessoas com deficiência, dentre outros. Assim, esses grupos demandam políticas públicas de ação afirmativa a fim de que Ihes sejam garantidas condições básicas de cidadania.

No que tange às políticas de ações afirmativas para a população negra, Vieira e Medeiros (2012, p. 197), apontam que "[...] é possível afirmar que $\circ$ racismo e a discriminação racial avançam no processo de desumanização e de não reconhecimento da cidadania dos negros [...], portanto, os indivíduos precisam perceber que as "diferenças" não devem ser motivos de desigualdades, como costumamos ver diariamente.

No campo educacional, Weller (2007, p. 135) afirma que "[...] é preciso realizar um esforço no sentido de integrar as políticas educacionais, uma vez que 'as desigualdades reforçam-se mutuamente' e o caminho para $\circ$ enfrentamento das diferenças produzidas a partir das múltiplas desigualdades requer ações articuladas e planejadas conjuntamente".

É por estes motivos que se travaram lutas para a implementação de políticas de ações afirmativas para a educação básica e superior no Brasil. Essas políticas constituem ações compensatórias e distributivas. A primeira tem caráter "reparatório", com vista a retificar injustiças e discriminações cometidas contra os negros, mulheres e indígenas, onde lhes foram negados direitos no passado, e que ainda hoje insistem em permanecer, sendo uma forma de "resgatar dívidas históricas". A segunda tem uma função mais atual e, está relacionada "[...] com a necessidade de se promover a redistribuição equânime dos direitos, benefícios, ônus, vantagens, riquezas, bens e obrigações pelos integrantes de uma sociedade. É uma busca de justiça no presente, ante a discriminação vivenciada no dia a dia" (ESTÁCIO, 2013, p. 4). Assim sendo:

Ela trata da promoção de oportunidades para aqueles que não conseguem ser representados de modo igualitário, e dessa forma o Estado seria o responsável em redistribuir os benefícios aos cidadãos, de maneira a tentar compensar e eliminar as desigualdades que os preconceitos e as discriminações efetuaram, e efetuam ainda, no presente. Tem-se assim, a adoção de políticas universalistas e complementares, com o fito de reduzir a desigualdade e a pobreza, 
e mesmo que não utilize o aspecto racial, devem reconhecer a discriminação de raça e etnia no Brasil (ESTÁCIO, 2013, p. 4).

Portanto, temos assim políticas públicas de ações distributivas e compensatórias que foram implementadas com a intenção de "minimizar" a exclusão desses grupos sociais, buscando promover a igualdade, uma vez que esses sujeitos não dispõem de iguais oportunidades, pois uma parte da sociedade brasileira foi "privilegiada" no acesso ao "acúmulo de saber", então, é óbvio que quando são oferecidos a eles melhores instrumentos de acesso ao saber, esses sujeitos terão maiores chances de ingressarem em uma Universidade, por exemplo.

No que se refere às Ações Afirmativas, e em especial às cotas no Ensino Superior, Estácio (2013, p. 11), diz ainda que:

[...] têm como objetivo não apenas coibir a discriminação do presente, mas, sobretudo, eliminar os efeitos persistentes (psicológicos, culturais e comportamentais) da discriminação do passado - justiça compensatória -, que tendem a se perpetuar. Esses efeitos se revelam na chamada discriminação estrutural, presentes nas desigualdades sociais entre grupos dominantes e os marginalizados. Figura também como meta, a implantação de uma diversidade e de maior representatividade dos segmentos excluídos nos mais diversos domínios de atividade pública e privada.

As primeiras discussões sobre as políticas de Ações Afirmativas se deram na Índia, na década de 1910, mas só em 1948 adotaram formalmente o acesso ao ensino público superior e ao mercado de trabalho. Já os Estados Unidos foram o primeiro país a utilizar ações afirmativas visando integrar grupos sociais que eram excluídos da sociedade americana. Foi a partir daí que se deram as discussões sobre o Brasil ter "importado" as políticas adotadas pelos EUA, mas isso se deu ao fato de terem se "espalhado" rapidamente por todo o país, mas apesar disso, elas tiveram características diferentes em cada local.

O debate sobre ação afirmativa não recai somente sobre as cotas raciais, mas algumas áreas como o mercado de trabalho, a educação, a saúde, a segurança, têm sido visadas na contemplação dessas políticas, e as mobilizações dos grupos sociais tem contribuído para que isto aconteça, 
pois eles lutam pela igualdade de direitos, denunciando as condições de exclusão, e ao mesmo tempo apresentam propostas para que os grupos que estiverem em condição de exclusão possam ser reconhecidos como qualquer outro.

Com relação às políticas de ação afirmativa no Ensino Superior, as Universidades públicas do Rio de Janeiro foram uma das primeiras a adotar as cotas para candidatos - oriundos da rede pública de ensino, negros, pessoas com deficiência e integrantes de minorias étnicas - aos cursos oferecidos, quando o Governador do Estado aprova a Lei Estadual n 3.524 de 28 de dezembro, reservando $50 \%$ das vagas de todos os cursos de graduação a esses candidatos, causando grandes polêmicas na sociedade brasileira, pois as universidades federais, estaduais e particulares, começam a adotar políticas de ação afirmativa. Assim, em respostas às críticas que foram surgindo, as leis estaduais $n^{\circ} 4151$ de 2003, e 5.074 de 2007, alteraram a proporção de distribuição de vagas, sendo definidos $20 \%$ para alunos oriundos da rede pública de ensino, 20\% para candidatos negros e 5\% para pessoas com deficiência ou indígena, tendo que atender ainda ao critério de carência socioeconômica. Por mais que as universidades estaduais tenham engendrado o assunto sobre as cotas, as universidades federais avançaram nesse processo, uma vez que "Entre as 70 universidades públicas que hoje adotam essas medidas, de um total de 96, são estaduais $44 \%$ e federais, 56\%" (DAFLON; FERES; CAMPOS, 2013, p. 308).

É um assunto que vem sendo discutido até os dias atuais, mas não foram os debates sobre as cotas nas universidades que engendraram essas discussões. Essas são questões que nos rememora aos conflitos da história da democracia racial e da identidade homogênea no Brasil. Assim,

A recusa de que a diferença possa, efetivamente, fazer diferença na construção da nação e na formulação de políticas públicas de combate à desigualdade, evidencia o quanto o paradigma universalista ainda é presente e se apresenta como horizonte a ser alcançado (VIEIRA; MEDEIROS, 2012, p. 195).

Por isso a importância de compreendermos e retornarmos ao passado como forma de entender todo esse processo das ações afirmativas, na 
busca por reivindicações de igualdade entre os cidadãos, pois, como afirma Moya (2012, p. 216), "[...] quando, nos dias de hoje, pensamos e discutimos as relações étnico-raciais brasileiras, estamos, na verdade, questionando a educação que recebemos e reproduzimos em busca de uma outra, não colonizada e não hierarquizada".

A política de ação afirmativa não se reduz às quotas para o Ensino Superior, ela é muito ampla e contempla diversos campos e grupos sociais que lutam pelo combate das desigualdades raciais e procuram ampliar as oportunidades sociais e educacionais para a população negra.

Segundo Estácio (2013, p. 2 - 3):

[...] as políticas de ação afirmativa, em especial as quotas para acesso de negros e indígenas ao ensino superior, fixam-se nas pautas de discussões políticas, sociais e acadêmicas brasileiras. Debate esse, muitas vezes, caracterizado pela desinformação da sociedade brasileira, pela formação de grupos de intelectuais, uns contrários outros favoráveis e a existência de pessoas, que acreditando na suposta democracia racial, fingem que nada está acontecendo.

Tomando como referência as discussões e experiências existentes no Brasil sobre as Políticas Públicas de Ações Afirmativas, em 2008 a Universidade Estadual do Sudoeste da Bahia (UESB), por meio da Resolução 36/2008, estabelece o Programa de Ações Afirmativas na Instituição, com as seguintes características: Sistema de reserva de vagas "combinadas" com cotas adicionais para todos os cursos de graduação da Universidade; Assistência Estudantil (permanência); e Integração com a Comunidade e Fortalecimento de Ações Externas de Assuntos Comunitários por meio de projetos e ações que contribuam para a formação continuada dos profissionais de ensino e apoio institucional aos cursos pré-vestibulares comunitários e populares.

Consta ainda, no Art. $2^{\circ}$ desta Resolução que:

Art. $2^{\circ}$ - O Programa de Ações Afirmativas da UESB consistirá em medidas especiais de discriminação positiva, com o objetivo de contribuir para a eliminação das desigualdades historicamente acumuladas, garantindo oportunidades de acesso e permanência aos segmentos sociais sub-representados, em decorrência de perdas provocadas pela discriminação e marginalização social por quaisquer motivos. 
A Resolução n 37/2008 instituiu o sistema de reserva de vagas e quotas adicionais no processo seletivo para todos os cursos de graduação da Universidade, num total de 50\%, assim distribuídos: $15 \%$ para estudantes que comprovem procedência de, no mínimo, 7 anos de ensino na Rede Pública e, dessa porcentagem, $35 \%$ do total das vagas foram destinadas a estudantes que se auto declararam negros. Ainda instituiu as quotas adicionais em cada curso de graduação.

Art. $2^{\circ}$ - Instituir, de forma complementar e cumulativa, a titulo de quotas adicionais, uma vaga para cada curso de graduação da UESB e em cada turno, para cada um dos seguintes segmentos sociais: indígena, quilombolas e pessoas com necessidade educativas especiais, mediante a apresentação de laudos antropológicos ou certidão de registro fornecidos pela Fundação Nacional do Índio - FUNAl e Fundação Cultural Palmares; e laudos médicos que atestem a existência de suas necessidades educativas especiais, respectivamente (UESB, 2008).

Ainda nessa Resolução, no Art. $8^{\circ}$, é concedida a isenção da taxa de inscrição no vestibular para aqueles que optarem pelo sistema de reserva de vagas ou quotas adicionais, para os oriundos de cursos pré-vestibulares comunitários e populares que tenham a comprovação e aqueles que cursaram o ensino em Rede Pública, correspondendo a $5 \%$ do total de inscritos pagantes no ano anterior.

O Art. $6^{\circ}$ da mesma Resolução aponta que o Programa de Ações Afirmativas de acesso estará em vigência durante 15 anos, havendo um acompanhamento anual pelo Comitê Gestor e que, a cada 5 anos será feita avaliações pelo CONSEPE, pensando em aperfeiçoar a implementação desta proposta na Universidade.

Na Resolução No 11/2008 é estabelecido o Programa de Assistência Estudantil que tem como objetivo contribuir para a garantia da permanência e conclusão dos alunos dos cursos oferecidos, mas para isso, os estudantes deverão comprovar carência econômica e social segundo os critérios adotados pela Instituição. 
Este Programa foi criado com a intenção de contribuir para a garantia da permanência e conclusão dos cursos pelos estudantes, viabilizando a igualdade de oportunidades aos discentes da UESB. Para tanto, foi definido que houvesse um sistema de avaliação quantitativa e qualitativa dos programas e projetos de assistência estudantil, analisando as relações entre assistência e evasão, assistência e rendimento acadêmico. Assim, foram definidos os seguintes Sub-programas de assistência, todos alocados na ProReitoria de Extensão e Assuntos Comunitários: permanência (moradia estudantil, alimentação, transporte, creche e atendimento à saúde); Desempenho Acadêmico (acompanhamento psicopedagógico, projetos de inclusão digital e ensino de línguas, eventos educativos etc.); Cultura, lazer e esporte; Assuntos da juventude (iniciativas de orientação).

\subsection{Estudantes cotistas negros no curso de Direito e suas trajetórias de escolarização}

Neste item do artigo, apresentamos três das categorias elaboradas a partir das entrevistas realizadas com os discentes cotistas negros do curso de Direito e que nos auxiliaram a compreender suas trajetórias de escolarização. Trajetória é aqui compreendida como: "toda trajetória social deve ser compreendida como uma maneira singular de percorrer o espaço social, onde se exprimem as disposições do habitus e reconstitui a série das posições sucessivamente ocupadas por um mesmo agente ou por um mesmo grupo de agentes em espaços sucessivos" (BOURDIEU, 1996, p. 120).

Conforme aponta Montagner (2007, p. 258):

perseguir uma trajetória significa acompanhar o desenrolar histórico de grupos sociais concretos em um espaço social definido por esses mesmos grupos em suas batalhas pela definição dos limites e da legitimidade dentro do campo em que se inserem. Seguramente a origem social é um holofote poderoso na elucidação dessas trajetórias, pois o habitus primário, devido ao ambiente familiar, é uma primeira e profunda impressão social sobre o indivíduo, que sofrerá outras sedimentações ao longo da vida. 


\subsection{A vivência/experiência do racismo}

Dos sujeitos entrevistados, Alan foi o que mais destacou situações em que sofreu preconceitos e racismo (tanto dentro da universidade quanto fora dela), relatando diversos momentos em que isso aconteceu. Uma dessas vivências se deu na escola, durante o Ensino Médio, onde sua professora de literatura apontou o dedo para as pessoas da sala - em sua maioria, negros, pobres e de bairros periféricos da cidade -, que nunca conseguiriam alcançar o Ensino Superior. Em seu percurso na universidade, ele diz que uma professora de Agronomia (curso que fazia antes), falou do seu cabelo, que na época estava grande, afirmando que ele estava se vitimizando por isso. Alan diz haver um racismo velado dentro da própria universidade. Silva Filho (2013, p.37), sobre essa questão, afirma que "[...] Nas escolas há uma discriminação explícita ou velada, mas sempre presente por parte de muitos profissionais da Educação, assim como no sistema de Saúde e no ingresso e ascensão no mercado de trabalho".

Lara já foi mais superficial em sua resposta no que se refere à influência da cor e outras variáveis, como condição socioeconômica, em seu percurso até entrar na universidade. Reconhece que esses elementos influenciaram, mas pontou que a opção pelo curso de Direito foi justamente por situações como essas. Segundo ela, no ensino formal não se discute a história dos negros, de como tudo aconteceu, que os livros retratam de forma superficial e que por isso o curso de Direito foi a sua escolha, baseada num processo de autoafirmação que ela vem construindo. Por ser um curso elitista, então ela queria mostrar que também poderia estar nesse espaço, como mulher e negra. Assim como Alan, ela também fala sobre a questão do "racismo velado" dentro da universidade, afirmando que:

[...] não se discute dentro da sala de aula a questão das cotas. Metade da turma é cotista, mas é uma coisa que não é discutida, a questão da negritude não é pautada e principalmente na universidade, são poucos os espaços que você tem e, quando tem, é o Novembro Negro, por exemplo. E é assim, ninguém discute, finge que não aconteceu... é como se não existisse. Depois que passou no vestibular acabou a discussão. Há 5 anos que a Uesb aderiu a 
política de cotas, e há pouco tempo no curso de Direito formou a primeira turma e foi uma desgraça, todo o percurso de história da turma, de preconceito, de racismo, de tensões muito grandes na sala, uma própria negação. Os professores eles são contrários em sua maioria, hoje alguns chegam a dizer '- Ah, hoje eu até que aceito', mas no começo era aquela questão, vai baixar a qualidade do curso, sendo que o curso já é uma merda, mas iria baixar a qualidade porque iriam entrar alunos menos preparados ou coisa do tipo, usando esse tipo de justificativa [...].

Essa fala de Lara pode ser muito bem relacionada com o que Reis e Tenório (2009, p. 8) constataram em uma pesquisa realizada com estudantes ingressos pelo sistema de reserva de vagas:

[...] observamos relatos de grande parte deles sobre o ambiente hostil dentro da sala de aula, assim como práticas discriminatórias pelas quais negros são percebidos de modo negativo no plano de suas possibilidades intelectuais. Nos chamados cursos nobres, atitudes como estas são, notadamente, mais frequentes.

É com base em questões como essas, levantadas por Alan e Lara, que Pereira (1996) discute sobre as relações raciais no Brasil, afirmando ser um país que enfrenta a pluralidade étnica e ambígua, e que por isso, vivemos em uma sociedade que descarta a história brasileira do que de fato foi o "verdadeiro racismo", no campo de crueldades, torturas físicas e extermínio de grupos étnicos, existindo um certo discurso social que é contrário à prática, pois "[...] tanto inibe manifestações negativas na avaliação 'do outro' racial como estimula a apologia da igualdade e da harmonia raciais entre nós, chegando ao extremo da sociedade brasileira" (PEREIRA, 1996, P. 76), ou seja, ninguém admite em suas falas, ter preconceitos, (re)afirmando com isso que o Brasil é um país "pacífico", sem discriminação, e para isso, utilizaram a cultura negra (tão diversificada) para mostrar a "face" harmoniosa e democrática do país. Sobre isso, o autor diz que:

O negro, enquanto grupo racial, permanece cercado em seus projetos de ascensão e participação sociais, contemplando de longe a sua cultura, ganhando cada vez mais status e prestígio, enquanto aguarda, lutando a sua maneira, que os seus pares sociais o reconheçam, também, como histórico e legítimo construtor da sociedade brasileira (PEREIRA, 1996, p.78). 
Blajberg (1996, p. 37) afirma que a discriminação racial passou a ser vista como uma "idiossincrasia", ou seja, foi considerada como algo praticado no Brasil individualmente e não pela sociedade. Essa foi uma forma de dizer que na sociedade brasileira já havia leis que justificavam a "igualdade" e que não havia racismo. Souza (2015), ao efetuar uma análise sobre o racismo à brasileira, identifica duas correntes teóricas que abordam essa temática atualmente: o racismo estrutural e o continuum de cor. No caso dessa última corrente, há o entendimento de que "a partir do sistema classificatório popular, que conseguiu encontrar 135 categorias possíveis de classificação racial, citadas pela própria população brasileira, seria impossível falar-se em uma nação bicolor". Portanto, para os autores dessa teoria, não há a possibilidade da existência de cotas raciais.

Quanto a Igor, ele afirma ter sofrido diversas situações de racismo, mas que só conseguiu perceber isso após sua entrada na universidade, com a disciplina de Sociologia, pois até então enxergava como algo "normal", mesmo que por muitas vezes tenha deixado de frequentar a escola por conta das piadinhas que sofria por parte de alguns colegas. Diz também que considera o Brasil um país onde o racismo e discriminação são velados, mascarados: "[...] mas que não deixa de acontecer certas piadas e preconceitos, por exemplo, pelo fato de ser cotista, pois as pessoas acreditam que os negros só entram na universidade porque foi pelo sistema de cotas".

Rodrigo, ao contrário de todos os outros entrevistados, diz que a sua cor não interferiu no seu percurso até a entrada na universidade, mas o que de fato interferiu foi a condição socioeconômica. Considera que por ser negro, já sofre "automaticamente" o racismo todos os dias, mas que ele sempre "releva", pois já tornou-se cotidiano. O pensamento de Rodrigo nos remete novamente aos teóricos do continuum de cor, para quem ações afirmativas socioeconômicas são mais viáveis no Brasil, pois para esses autores, o problema entre nós é de distribuição de renda apenas, não de racismo.

Concordamos com Santos (2005, p.15), para quem: 
O racismo contra os negros no Brasil tem sido praticado desde o primeiro momento da chegada forçada destes seres humanos no país, uma vez que foram trazidos como escravos (...). A profunda desigualdade racial entre negros e brancos em praticamente todas as esferas sociais brasileiras é fruto de mais de quinhentos anos de opressão e/ou discriminação racial contra os negros, algo que não somente os conservadores brasileiros, mas uma parte significativa dos progressistas recusam-se a admitir.

Foi possível observar, portanto, que todos os sujeitos, de alguma maneira, já vivenciaram a experiência do racismo em algum momento de sua vida. No caso de Rodrigo, mesmo que ele não considere a sua cor como elemento que possa ter interferido no seu processo de escolarização até a entrada na universidade, ele também vivenciou situações de preconceito racial praticamente todos os dias, mas isso foi naturalizado, a ponto de afirmar que não se importa mais.

A narrativa de Rodrigo nos leva a concluir que o racismo é empregado como ideologia e como discurso, produzindo determinados tipos de sujeitos. Foi Fanon (2008, p.85) que em sua análise pontuou que devemos partir do seguinte princípio: "uma sociedade é racista ou não o é. Enquanto não compreendermos essa evidência, deixaremos de lado muitos problemas". Segundo o autor martinicano, foi o discurso colonial, sempre construído em terceira pessoa, que informou o que é o negro. No caso brasileiro, isso não foi diferente. As teorias raciais construídas no século XIX produziram uma representação sobre o que é o negro. É por meio dessa representação que o discurso sobre o negro se perpetua, pois o racismo tem seu próprio léxico.

No caso de Igor, ele diz que antes de entrar na universidade, não tinha ideia de que as piadinhas que seus colegas faziam eram vistas como racismo e que só passou a enxergar isso após a sua formação dentro da universidade. Piadas sobre os negros nos fazem pressupor que em nosso país a brincadeira e a diversão são pautadas pelo racismo, afinal,

as piadas são uma das piores ferramentas de perpetuação de preconceitos e discriminações, uma vez que são disfarçados de inocência, como se fossem lançados com a melhor das boas intenções: a de fazer rir, a de descontrair. E é dessa maneira que essa modalidade de discurso ganha terreno (VIEIRA e MEDEIROS, 2014, p.235). 
Alan e Lara sempre enxergaram as experiências com o racismo em seu cotidiano e buscaram discutir essas questões com seu grupo social.

A população negra, se você vai oferecer um acesso à educação e em que essa educação ela não represente, por exemplo: quantos os professores negros você tem na Universidade? Quantos doutores? OU em cargos de mais importância... e a gente precisa dar essa resposta urgente e ligeira para essa população... para a gente (Alan).

\title{
3.4 As ações afirmativas no ensino superior
}

\begin{abstract}
As políticas de ação afirmativa na Educação Superior no Brasil tornaram-se pauta de reivindicação de movimentos sociais, propostas de políticas públicas de Estado, no âmbito federal, âmbito estadual e nas universidades, e temas de debates muito intensos na sociedade brasileira, com uma ênfase maior nos últimos anos. Essas políticas de ação afirmativa se apresentam como políticas públicas adotadas pelos governos, leis propostas nos legislativos, decisões judiciais, iniciativas de entidades da sociedade civil ou empresas, todas essas com o objetivo de combater a discriminação historicamente construída contra determinados grupos sociais, minoritários ou majoritários na sociedade (SILVA FILHO, 2013, p. 9).
\end{abstract}

Pensando nas ações afirmativas - principalmente nas políticas públicas voltadas para o Ensino Superior -, buscamos identificar durante as entrevistas - que os entrevistados pensam sobre a universidade, bem como a sua opinião sobre as ações afirmativas da universidade.

Alan diz ter entrado na Uesb pelo sistema de cotas e se posicionou de maneira bastante crítica no que se refere à importância dessas políticas, considerando todo o marco histórico pelo qual os negros passaram e que não são levados em consideração:

É preciso essas políticas afirmativas como cotas para concurso público também, porque a conjuntura histórica mesmo de como foi a construção do povo brasileiro, como foi a construção dos negros, de tudo aquilo... de como foi trazido, porque foram trazidos e de forma foram trazidos e depois o pós, o (ranço) que ficou do processo escravocrata no Brasil e tudo aquilo que ele desencadeou, pela negação de uma população ou por julgar de uma incapacidade intelectual, capacidade de exercer outras funções que não seja todas aquelas renegadas pela população escrava, e isso perdurou e perdura até hoje. O Brasil não possui um programa... a educação não é voltada à educação de base, em várias instâncias: em trabalho, na família... em vários setores, o papel do negro é sempre 
julgado e dados e pesquisas apontam mesmo. Apesar de ser a maioria da população brasileira, os negros ainda são a minoria nas Universidades, isso porque foi e é uma negação ao acesso à educação, porque a gente não poderia ter acesso e educação de forma alguma, e essa política de ações afirmativas é uma maneira rápida de dar uma oportunidade e uma resposta ligeira, instantânea, na avaliação social que a gente tira.

Notamos que Alan tem uma formação política que the possibilita discutir sobre o porquê de ter sido um "passo" tão importante no Brasil a implementação de políticas públicas de ações afirmativas. Ele é um estudante que sempre se faz presente em diversos cursos de extensão que abordam as questões de raça e gênero na universidade, o que lhe possibilita acesso às discussões sobre o tema das ações afirmativas.

Lara também é cotista e disse que enxerga o sistema de cotas como uma medida necessária, pois assim como Alan, segundo ela, por mais que a maioria da população brasileira seja composta por negros, estes são a minoria nas universidades, por isso a necessidade das ações afirmativas:

[...] Eu acho que é uma questão de você pautar uma igualdade material, porque a necessidade de entrar num curso superior é urgente, a gente não pode esperar, essa desculpa que o povo usa de que '- Ah, porque precisa investir na educação básica'... a gente precisa entrar na universidade na medida em que a gente está vivendo agora.

Sobre esta questão, Silva Filho $(2013$, p. 32) diz ainda que:

A ação afirmativa não se caracteriza por privilégio ou construção de espaços de usufruto de condições discriminatórias, mas é uma medida ou conjunto de medidas para garantir que grupos socialmente discriminados, historicamente sem acesso às condições de educação, renda, saúde e trabalho, e que não teriam condições de competir no mercado, possam efetivamente partir de um patamar similar a de outras pessoas [...]. Assim, as ações afirmativas também precisam ser as cotas, as reservas de vagas.

Igor, também cotista, fala do quanto é importante a igualdade material (que Lara também comenta), uma vez que muitas pessoas têm mais oportunidades e prioridades que outras. Ele relata que quando estava no Ensino Médio as pessoas Ihe perguntavam se ele iria optar por cotas e a maioria dessas pessoas (brancas) optaria por cota social (por conta da 
questão da escola pública), mas principalmente porque consideravam que teriam maiores chances de ingressar na universidade, por "ser mais fácil" entrar por cotas. E Igor, assim como essas pessoas, não enxergava as cotas como uma política pública e que havia toda uma questão histórica e de lutas que culminaram com as ações afirmativas. Ele considerava simplesmente como a "concessão de fácil acesso à universidade".

Igor, assim como todos os outros, entrou na universidade pelo sistema de cotas e diz considerar as ações afirmativas como "[...] um meio necessário para o ingresso de uma classe que não é abastada na sociedade e que precisa ser vista, mas que esse sistema de cotas e ações afirmativas não precisaria se o sistema funcionasse como deveria", ou seja, ele não discorda das ações afirmativas, mas diz que se a escola pública funcionasse como a rede privada funciona - em se tratando de conhecimento -, assim como todos os entrevistados já haviam criticado a falta de preparo dos estudantes da rede pública, não precisaria de cotas, pois estariam todos no mesmo patamar.

Igor aponta para o fato de que enquanto isso não acontecer, as ações afirmativas são vistas como um meio para que se insira essa "minoria" nas universidades. Lara já tem uma visão mais realista quanto à questão de melhorar a educação básica para não precisar das ações afirmativas, pois considera essas ações como uma maneira rápida de dar uma resposta aos grupos socialmente discriminados, ao invés de esperar que seja "reformulada" toda a educação básica, pois essa é uma medida que demanda muito mais tempo e para a nossa sociedade atual necessitamos de respostas urgentes e imediatas.

Com relação ao que os entrevistados pensam sobre a universidade, bem como estar nela, todos tiveram opiniões as mais diversas e isso é muito interessante, pois nos faz refletir sobre qual é, ou tem sido de fato, o papel da universidade no que se refere à formação desses sujeitos.

Dos sujeitos entrevistados, dois criticaram a universidade, considerando que ela ainda reproduz muito do que a sociedade é, como um espelho e seu reflexo, "repetindo" muitos dos modus operantes do racismo e opressões: 
Alan mesmo relata ter vivenciado diversas situações de racismo por professores da própria universidade; Lara diz que esperava um pouco mais de dinamicidade da universidade, pois há poucos espaços de interação, uma vez que considera o seu curso a mesma coisa que estar num "escolão", por ser uma questão muito tradicional:

[...] a universidade ela não chega a contemplar aquilo que ela propõe, de fazer ensino, pesquisa e extensão, de estar com o olhar um pouco mais aberto, poder ter uma consciência melhor, uma visão de mundo melhor... a universidade é tão complexa quanto a sociedade, não vejo com um olhar muito otimista não (Lara).

Já Igor e Rodrigo têm uma visão bem mais positiva da universidade e do curso de Direito:

\footnotetext{
Meu conhecimento mudou totalmente... trouxe vários horizontes, várias vertentes que eu desconhecia, tanto política como ideológica, e social. E o Direito pra mim, eu acho que é um transformador de várias realidades, tanto a minha como a de tantas pessoas que são desassistidas, que precisam da verdadeira justiça que hoje praticamente não existe (lgor).
}

Eu estou muito feliz em estar aqui na Uesb, e acredito que irei me realizar profissionalmente e na vida também. Acredito que aqui é o meio de ascensão social, não só como profissional, mas que eu possa levar isso pra vida, possa ajudar as pessoas, e me interagir melhor (Rodrigo).

Percebeu-se que a universidade, como espaço da construção do conhecimento, ainda reproduz situações de racismo. No curso de Direito, o segundo mais concorrido do campus de Vitória da Conquista, poucos são os projetos de pesquisa e extensão do corpo docente. Também não há formação pedagógica para os professores. Verificamos que a aprovação no exame da Ordem dos Advogados do Brasil é apontada como elemento que define a qualidade do curso.

Apesar disso, muitos desses estudantes encontram nas bolsas de IC ou projetos de extensão em outros departamentos da UESB, uma forma de manter-se nesse espaço, uma vez que suas famílias, sozinhas, não conseguiriam arcar com os gastos financeiros para sua permanência no ensino superior. Apesar das críticas, os sujeitos entrevistados não deixaram de 
considerar a importância da academia para a formação e construção do conhecimento, bem como a oportunidade para uma ascensão social.

\subsection{Projeto de futuro}

Projeto é aqui entendido conforme nos aponta Velho (2003, p.101): "conduta organizada para atingir finalidades específicas", processo marcado por multiplicidades e heterogeneidades. Para ele, o sujeito traça seus projetos a partir do campo de possibilidades, ou seja, "o que é dado com as alternativas construídas do processo sóciohistórico e com o potencial interpretativo do mundo simbólico da cultura".

Em relação aos projetos de estudo ao longo do processo educacional, bem como os planos que têm para quando terminar a faculdade, os quatro sujeitos entrevistados tiveram e têm projetos diferenciados: Igor ainda não sabe ao certo o que quer fazer quando terminar a graduação; pensa na possibilidade de fazer magistratura, promotoria ou advogar, mas atualmente estava estudando para concurso, na tentativa de conciliar com a faculdade, sendo uma maneira de estar adquirindo uma renda enquanto estuda. Já Rodrigo diz que não pensa como a maioria da sua turma, que quer fazer concurso, pois ele quer mesmo é advogar, mais especificamente numa área social. Alan e Lara já têm outro viés, que é a de fazer um mestrado: Alan quer tentar um mestrado que aborde as relações etnicorraciais e Lara quer um que esteja voltado para a área de direitos humanos.

Percebemos que os projetos de estudo desses sujeitos, ao longo de processo educacional, foi basicamente $\bigcirc$ que a escola pública "ensinava/transmitia", como eles mesmos dizem, pois, segundo Alan,

existe uma deficiência no que se refere ao ensino público, que é justamente quando se discute a questão dos pais que têm melhores condições e optam por colocar os seus filhos na rede privada, onde ele vai obter maior preparação, comparada aos estudantes das camadas populares, que estudam todo o período educacional em rede pública. Quando é chegada a hora de prestar o vestibular, eles não estão com o mesmo nível de conhecimentos que os jovens que estudaram sempre em escola particular, fazendo com que as vagas nas universidades públicas sejam ocupadas, em sua maioria, pelos 
jovens de classe alta, principalmente nos cursos mais concorridos como Medicina e Direito.

É importante frisar que a função da escola pública não é a aprovação no vestibular, mas sim a garantia de acesso a conhecimentos dos mais diversos campos do saber que possibilitem ao sujeito a convivência numa sociedade cada vez mais desigual. Na verdade, o acesso ao ensino superior por meio do exame vestibular também precisa ser problematizado na escola, a fim de que os estudantes compreendam o quanto a meritocracia se encontra presente no acesso ao conhecimento.

Verificamos que os nossos entrevistados valeram-se de algumas estratégias para ingressar na universidade, tais como investimento pessoal na forma de muitas horas diárias de estudo e cursinho pré-vestibular comunitário.

Segundo Igor, ele e mais um grupo de amigos que almejavam o Ensino Superior eram autodidatas, pois tudo que o professor passava em sala, eles se organizavam em grupos de estudo e reforçavam em casa, para obterem mais chances de ingressar no Ensino Superior público. Essa situação caminha na direção daquilo que é apontado por Bourdieu (2008, p. 44):

\begin{abstract}
Da mesma forma que os jovens de camadas superiores se distinguem por diferenças que podem estar ligadas a diferenças de condição social, também os filhos das classes populares que chegam até o ensino superior parecem pertencer a famílias que diferem da média de sua categoria, tanto por seu nível cultural global como por seu tamanho [...]. A presença no círculo familiar de pelo menos um parente que tenha feito ou esteja fazendo curso superior testemunha que essas famílias apresentam uma situação cultural original, quer tenham sido afetadas por uma mobilidade descendente ou tenham uma atitude frente à ascensão que as distingue do conjunto das famílias de sua categoria.
\end{abstract}

Ou seja, Igor se destacou frente aos demais colegas, sendo que a sua família apresentou um nível cultural global diferente das famílias dos seus amigos que não buscaram o Ensino Superior. Segundo ele, em sua família já havia um histórico de pessoas que ingressaram no Ensino Superior e isso lhe influenciou muito. 
Já Alan obteve apoio dos pais nos estudos, mas que não havia influencia pela busca da graduação, já que, segundo ele, seus pais não tinham ideia da sua importância. Quem the deu apoio para entrar na universidade foi a sua madrinha e a filha dela, ou seja, pessoas provenientes de outras redes, mas que de certa forma estão interligadas, funcionando como capital social.

No terceiro ano do Ensino Médio Rodrigo teve a oportunidade de fazer um cursinho pré-vestibular público em sua cidade, mas afirma "que o mesmo era muito defasado, e que nunca iria formar os alunos no mesmo nível que aqueles que fizeram um cursinho particular".

Notamos que os sujeitos entrevistados estão a todo o momento, de alguma forma, criticando o Ensino Público. Eles criaram estratégias e projetos de estudo quando perceberam que somente o que estudavam em sala não seria suficiente para ingressar na universidade. As cotas, nesse sentido, são fundamentais, pois partem da perspectiva de que os desiguais precisam ser tratados de forma desigual.

\section{CONSIDERAÇÕES FINAIS}

Neste artigo, discutimos as percepções de estudantes negros cotistas do curso de Direito da UESB acerca das ações afirmativas e do racismo. A análise possibilitou compreender o papel da família, parentes, amigos, vizinhos, tios, avós, que teve muito destaque nas falas dos entrevistados, sendo de extrema importância influências como essas na vida dos sujeitos no que se refere à suas trajetórias e no processo de ascensão social, sendo a família a "fonte" primordial, tendo em vista que conforme Teixeira (2003, p. 244) afirma "São essas redes que estabelecem relações de amizade e solidariedade entre pessoas e famílias de diferentes classes sociais e de diferentes identidades raciais apoiando, incentivando e mantendo projetos e trajetórias de ascensão".

Todos os sujeitos já vivenciaram em algum momento situações de preconceito e/ou racismo, seja fora ou no interior da universidade, mas Alan foi o que mais relatou casos impressionantes sobre esta questão. No que se 
refere às ações afirmativas, todos eles entendem e consideram-nas importantíssimas, principalmente no que se refere às cotas para o ensino superior, aumentando as possibilidades de ingresso dos negros à esse espaço, uma vez que os quatro consideraram-se como negros e cotistas.

Cada um dos quatro sujeitos entrevistados nos proporcionou, através de suas falas, conhecermos um pouco mais das suas histórias/trajetórias de vida até o ingresso no ensino superior, permitindo dialogar sobre as diversas situações em que passaram até alcançar essa etapa.

\section{REFERÊNCIAS}

BLAJBERG, S. As idiossincrasias raciais brasileiras na formulação das políticas públicas em vista da eliminação do apartheid formal na África do Sul. In: MUNANGA, K. Estratégias e políticas de combate à discriminação racial. São Paulo: Editora da Universidade de São Paulo; Estação Ciência, 1996.

BOURDIEU, P. Escritos de Educação. Maria Alice Nogueira e Afrânio Catani (Orgs.). 10. ed. Petrópolis, RJ: Vozes, 2008.

BOURDIEU, P. Razões práticas: sobre a teoria da ação. Campinas: Papirus, 1996.

CARVALHO, S. S.; EUGENIO, B. G. A aquisição do capital linguístico em alunos dos meios populares. In: EUGENIO, B. (Org.). Processo de escolarização nos meios populares: itinerários de pesquisa. São Paulo: Scortecci, 2011.

DAFLON, V. T.; FERES JUNIOR, J.; CAMPOS, L. Ao. Ações afirmativas raciais no ensino superior público brasileiro: um panorama analítico. Cadernos de Pesquisa, v. 43, n. 148, p.302-327,2013.

ESTÁCIO, M. A. F. Dialogar com a diferença: escuta das vozes favoráveis e contrárias as quotas étnicas. Anais da $36^{a}$ Reunião Nacional da ANPEd. Goiânia, 29 de Setembro a 02 de Outubro de 2013.

FANON, F. Pele negras, máscaras brancas. Salvador: Edufba, 2008.

FERES JR., J. Ação afirmativa no Brasil: fundamentos e críticas. Econômica, vol.6, n.2, p.291-312, 2004.

MINAYO, M. C. de S. (Org.). Pesquisa social: teoria, método e criatividade. 13. ed. Rio de Janeiro: Vozes, 1994.

MONTAGNER, M. A. Trajetórias e biografias: notas para uma análise bourdiesiana. Sociologias, ano 9, n. 17, p.240-264, 2007.

MOYA, T. S. Educação para as relações étnico-raciais em perspectiva contemporânea. In: SILVEIRO, V. R.; MATTIOLI, É. A. K.; MADALENA, T. F. L. M. Relações étnico-raciais: um percurso para educadores. São Carlos: EDUFSCAR, 2012. 
NEGRÃO, M. M. Políticas de acesso do negro na educação superior no governo Lula: além das cotas? Dissertação (Mestrado em Educação), Universidade Tuiuti do Paraná, Curitiba, 2011.

PEREIRA, J. B. B. Racismo à brasileira. In: MUNANGA, K. Estratégias e políticas de combate à discriminação racial. São Paulo: Editora da Universidade de São Paulo: Estação Ciência, 1996.

REIS, D. B.; TENÓRIO, R. M. Políticas públicas de acesso e permanência da população negra no ensino superior - um debate em curso. Anais do Encontro da $\quad$ ANPAE, $2009 . \quad$ Disponível em: www.anpae.org.br/congressos_antigos/simposio2009/83.pdf. Acesso em 10 out.2017

SALVADOR, A. C. Ação afirmativa na PUC-Rio: a inserção de alunos pobres e negros. Rio de Janeiro: Editora PUC Rio, 2011.

SILVA FILHO, P. Políticas de ação afirmativa na educação brasileira. Jundiaí: Paco Editorial, 2013.

SOUZA, C. Sim, somos racistas: análise sociológica do racismo à brasileira. Curitiba: Appris, 2015.

TEIXEIRA, M. de P. Negros na universidade: identidade e trajetórias de ascensão social no Rio de Janeiro. Rio de Janeiro: Pallas, 2003.

UESB. Resolução $n^{\circ} \mathbf{3 6 / 2 0 0 8}$. Dispõe sobre o Programa de ações afirmativas da UESB. Vitória da Conquista, 2008.

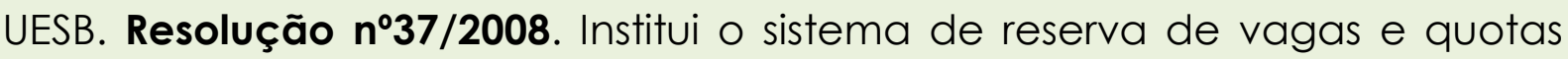
adicionais para acesso aos cursos de graduação. Vitória da Conquista, 2008.

UESB. Resolução $n^{\circ} \mathbf{1 1 / 2 0 0 8}$. Dispõe sobre o Programa de permanência na UESB. Vitória da Conquista, 2008.

VELHO, G. Projeto e metamorfose: antropologia das sociedades complexas. 3.ed. Rio de Janeiro: Jorge Zahar Editor, 2003.

VIEIRA, P. A. dos S.; MEDEIROS, P. M. Ação afirmativa no Brasil e no mundo: notas para um debate em curso. In: SILVEIRO, V. R.; MATTIOLI, E. A. K.; MADALENA, T. F. L. M. Relações étnico-raciais: um percurso para educadores. São Carlos: EDUFSCAR, 2012.

VIEIRA, P. A. S.; MEDEIROS, P. M. Pela desracialização da experiência: discurso nacional e educação para as relações étnico-raciais. In: MISKOLCl, Richard; LEITE JUNIOR, J. (Org.). Diferenças na educação: outros aprendizados. São Carlos: Edufscar, 2014.

WELLER, W. Diferenças e desigualdades na Universidade de Brasília: experiências de jovens negras e suas visões sobre o sistema de cotas. Revista Política e Sociedade, v. 6, p. 133-158, 2007.

Recebido em: Janeiro de 2017 Aprovado em: Janeiro de 2018 